\title{
PEMBELAJARAN BERBASIS PROJEK (PROJECT BASED LEARNING) \\ PADA PENGAJARAN ENGLISH DRAMA APPRECIATION DENGAN MENGGUNAKAN MEDIA PEMENTASAN DRAMA BERBAHASA INGGRIS 'SANGKURIANG'
}

\author{
Haryati Sulistyorini
}

haryati.sulistyorini@dsn.dinus.ac.id

Universitas Dian Nuswantoro Semarang

\begin{abstract}
This paper entitled 'Project Based Learning in the Subject English Drama Apprectaion, Using English Drama Performance 'Sangkuriang' has a purpose for learners and teachers in literature to give an assumption that literary criticism could be done not only by using reception theory but also used another model in teaching like Project Based Learning. The Project Based Learning in English Drama Appreiation with a play performance, Sangkuriang also has the main purpose to introduce and promote the tourism object of Tangkuban Perahu as the popular tourism object in Indonesia especially in West of Java. This is usually called by travelling literature which also has a function to promote and popular the tourist objects. Descriptive qualitative is used to describe the data which is acquired in the project based learning.The result shows that teaching learning in English Drama Appreciation which is done by the project based learning is able to give students in the interpretation on a literary work in a play perform like Sangkuriang.
\end{abstract}

Keywords: tourism, literature, drama, Sangkuriang

Pengajaran berbasis projek dalam sastra merupakan salah satu cara untuk dapat membuat proses belajar dan mengajar menjadi lebih efektif dan memberikan hasil yang diharapkan. Mata kuliah Drama merupakan salah satu subjek pembelajaran yang lebih tepat digunakan untuk model pembelajaran berbasis projek tersebut, karena Drama dapat menggunakan media yang dirasa lebih tepat digunakan pengajar untuk lebih mengenalkan ilmu dan jenis sastra keada peserta didik yag dalam hal ini mahasiswa.

Drama merupakan salah satu jenis sastra/literary genre yang menyajikan pertunjukan seni dalam bentuk pementasan. Melalui pertunjukan drama tujuan sastra yang bersifat menghibur tersampaikan, pesan/amanat cerita yang bermanfaat dan 
Haryati Sulistyorini, Pembelajaran Berbasis Projek (Project Based Learning) pada Pengajaran English Drama Appreciation, Menggunakan Media Pementasan Drama Berbahasa Inggris 'Sangkuriang'

merefleksikan hidup manusia juga tersampaikan. Reaske (1966) dalam bukunya How to Analyze Drama mendefinisikan drama sebagai berikut:

A drama is a work of literature or a composition which delineates life and human activity by means of presenting various actions of - and dialogues between a group of characters (Christopher Rusell Reaske,5:1966)

Drama merupakan bagian dari karya sastra yang tidak hanya dibaca namun juga dipentaskan dengan media dialog. Pertunjukan drama dapat berupa tragedi maupun komedi. Biasanya cerita yang diangkat adalah cerita yang memberikan pesan dan amanat yang bermanfaat bagi masyarakat, baik drama realism maupun legenda. Apapun bentuk pertunjukan sebuah drama, yang paling utama adalah bagaimana kegiatan pementasan tersebut bisa menjadikan drama sebagai salah satu dari karya sastra yang berperan dalam perkembangan seni. Karya sastra drama tidak hanya berhubungan dengan pertunjukan seni, namun juga melalui karya sastra yang dipertunjukan tersebut kita dapat mengenal sejarah, hikayat dan legenda. Legenda sebagai bagian dari karya sastra memberikan wacana bukan hanya sebagai penghibur namun juga memberikan pengetahuan lain seperti kearifan lokal, sejarah dan wisata. Melalui naskah legenda kita dapat mengenal beberapa pengetahuan yang berhubungan dengan pariwisata karena biasanya sebuah cerita legenda atau folk juga menyajikan pengetahuan wisata melalui pelataran cerita yang dibawakan. Karya sastra berjenis legenda tersebut tidak hanya dapat didapat dengan cara membaca teks sastra legenda namun juga dapat melalui pertunjukan atau pementasan drama. Jadi singkatnya, legenda dimasukkan dalam pementasan drama dan membawa para penikmat drama legenda tersebut dalam sebuah wisata sastra.

Pengajaran English Drama Appreciation merupakan pengajaran sastra apresiasi dengan metode pengajaran berbasis projek yaitu pementasan drama. Sebagai objek pementasan, ide cerita dapat berasal dari karya sastra berjenis apapun dan berasal dari negara manapun. Objek pementasan drama pada makalah ini diambil dari legenda Indonesia yang berasal dari daerah Jawa Barat yaitu Sangkuriang, sebuah legenda tentang terjadinya Gunung Tangkuban Parahu. Projek tersebut disiapkan selama satu semester dengan kerangka tujuan untuk menanamkan kearifan lokal pada mahasiswa 
peserta didik selain juga mengenalkan lebih dalam lagi legenda terjadinya Gunung Tangkuban Parahu.

Tangkuban Parahu adalah salah satu gunung yang terkenal di Jawa Barat bahkan sudah lama menjadi tempat pariwisata. Destinasi wisata tersebut mampu menyerap wisatawan baik asing maupun domestik dengan jumlah yang cukup banyak. Objek wisata yang diangkat dari cerita legenda Sangkuriang dan Dayang Sumbi tersebut menjadi bagian dari sastra untuk dapat dijadikan sebagai salah satu karya sastra lisan dan dapat digolongkan sebagai cerita rakyat atau folk. Melalui cerita legenda atau cerita rakyat berjenis folk tersebut sastra dapat berfungsi bukan hanya sekadar sebagai karya seni yang bersifat imajinatif dan menghibur, namun juga berperan dalam memajukan pariwisata di Indonesia.

Pertunjukan pementasan drama Sangkuriang tersebut adalah model pembelajaran apresiasi sastra berbasis projek dengan mengedepankan nilai-nilai kearifan lokal (local wisdom) guna mengenalkan budaya lokal pada peserta didik generasi muda. Pembelajaran karya legenda atau cerita dongeng lokal dengan metode tersebut memungkinkan bagi para pembelajar sastra untuk lebih memahami isi dan makna cerita sehingga diharapkan mampu menjelaskan kekayaan budaya Indonesia sebagai aset pariwisata. Pementasan drama lokal dengan media bahasa internasional yaitu bahasa Inggris diharapkan mampu mengenalkan wisata kekayaan budaya Indonesia pada dunia internasional sehingga apa yang menjadi tujuan sastra dalam peran serta di dunia pariwisata dapat terwujud melalui wisata sastra tersebut.

\section{KAJIAN TEORETIS}

\section{Drama}

Drama merupakan salah satu dari karya sastra yang menggunakan media dialog tokoh untuk menghantarkan isi cerita. Seperti karya sastra lain, novel, poetry dan film, drama juga bersifat imajinatif dan menghibur, ceritanya terinspirasi oleh kehidupan masyarakat. Drama tidak hanya diciptakan untuk dibaca, melainkan juga untuk 
Haryati Sulistyorini, Pembelajaran Berbasis Projek (Project Based Learning) pada Pengajaran English Drama Appreciation, Menggunakan Media Pementasan Drama Berbahasa Inggris 'Sangkuriang'

dipentaskan. Penyelenggaraan sebuah pertunjukan drama tidak lepas dari berbagai unsur drama seperti properti, pencahayaan, tata rias, ekspresi dan gerak, karena unsurunsur tersebut memang harus ada dalam sarat berjalannya sebuah pementasan drama. Hal tersebut sesuai dengan apa yang dikatakan oleh Mario Klarer dalam Introduction to Literary Studies sebagai berikut:

The dramatic or performing arts, however, combine the verbal with a number of non-verbal or optical-visual means, including stage, scenery, shifting of scenes, facial expressions, gestures, make-up, props, and lighting. This emphasis is also reflected in the word drama itself, which derives from the Greek "draein" ("to do," "to act"), thereby referring to a performance or representation by actors. Drama (Klarer, 2004)

Landasan Teori Project Based Learning John Dewey dan Kelas Demokratis Eureka Pendidikan. Metode proyek berasal dari gagasan John Dewey tentang konsep "Learning by doing" yaitu proses perolehan hasil belajar dengan mengerjakan tindakan-tindakan tertentu sesuai dengan tujuan (Grant, 2002). Kelas demokratis mengandung arti bahwa siswa dibagi dalam kelompok-kelompok kecil untuk menyelesaikan proyek yang menarik dan pilihan siswa sendiri.

Karakteristik Project Based Learning memiliki karakteristik yang membedakan model yang lain. Karakteristik tersebut, antara lain : 1. Centrality Project Based Learning, yaitu proyek menjadi pusat dalam pembelajaran. 2. Driving Question Project Based Learning difokuskan pada pertanyaan atau masalah yang mengarahkan siswa untuk mencari solusi dengan konsep atau prinsip ilmu pengetahuan yang sesuai. 3. Constructive Investigation Project Based Learning, siswa membangun pengetahuannya dengan melakukan investigasi secara mandiri (guru sebagai fasilitator). 4. Autonomy Project Based Learning menuntut student centered, siswa sebagai problem solver dari masalah yang dibahas. 5. Realisme Kegiatan siswa difokuskan pada pekerjaan yang serupa dengan situasi yang sebenarnya. Aktifitas ini mengintegrasikan tugas otetik dan menghasilkan sikap profesional (Thomas, 2000). Tujuan Project Based Learning Setiap model pembelajaran pasti memiliki tujuan dalam penerapannya. 
5 Lกी TEE, Volume 16 Nomor 1, Maret 2020

Tujuan Project Based Learning (PBL):

1. Meningkatkan kemampuan peserta didik dalam pemecahan masalah proyek;

2. Memperoleh pengetahuan dan keterampilan baru dalam pembelajaran;

3. Membuat peserta didik lebih aktif dalam memecahkan masalah proyek yang kompleks dengan hasil produk nyata;

4. Mengembangkan dan meningkatkan keterampilan peserta didik dalam mengelola bahan atau alat untuk menyelesaikan tugas atau proyek;

5. Meningkatkan kolaborasi peserta didik khususnya pada PBL yang bersifat kelompok.

\section{Langkah-langkah Project Based Learning}

Langkah-langkah project based learning sebagaimana yang dikembangkan oleh The George Lucas Educational Foundation (2005) terdiri dari:

a. Penentuan Pertanyaan Mendasar (Start With the Essential Question) Pembelajaran dimulai dengan pertanyaan esensial yaitu pertanyaan yang dapat memberi penugasan kepada siswa dalam melakukan suatu aktivitas. Topik penugasan sesuai dengan dunia nyata yang relevan untuk siswa. dan dimulai dengan sebuah investigasi mendalam.

b. Mendesain Perencanaan Proyek (Design a Plan for the Project) Perencanaan dilakukan secara kolaboratif antara guru dan siswa. Dengan demikian siswa diharapkan akan merasa "memiliki" atas proyek tersebut. Perencanaan berisi tentang aturan main, pemilihan aktivitas yang dapat mendukung dalam menjawab pertanyaan esensial, dengan cara mengintegrasikan berbagai subjek yang mungkin, serta mengetahui alat dan bahan yang dapat diakses untuk membantu penyelesaian proyek.

c. Menyusun Jadwal (Create a Schedule) Guru dan siswa secara kolaboratif menyusun jadwal aktivitas dalam menyelesaikan proyek. Aktivitas pada tahap ini antara lain: 
Haryati Sulistyorini, Pembelajaran Berbasis Projek (Project Based Learning) pada Pengajaran English Drama Appreciation, Menggunakan Media Pementasan Drama Berbahasa Inggris 'Sangkuriang'

a) Membuat deadline (batas waktu akhir) penyelesaian proyek,

b) Membawa peserta didik agar merencanakan cara yang baru,

c) Membimbing peserta didik ketika mereka membuat cara yang tidak berhubungan dengan proyek

d) Meminta peserta didik untuk membuat penjelasan (alasan) tentang pemilihan suatu cara.

d. Memonitor siswa dan kemajuan proyek (Monitor the Students and the Progress of the Project) Guru bertanggungjawab untuk melakukan monitor terhadap aktivitas siswa selama menyelesaikan proyek. Monitoring dilakukan dengan cara menfasilitasi siswa pada setiap proses. Dengan kata lain guru berperan menjadi mentor bagi aktivitas siswa. Agar mempermudah proses monitoring, dibuat sebuah rubrik yang dapat merekam keseluruhan aktivitas yang penting.

e. Menguji Hasil (Assess the Outcome) Penilaian dilakukan untuk membantu guru dalam mengukur ketercapaian standar, berperan dalam mengevaluasi kemajuan masing- masing siswa, memberi umpan balik tentang tingkat pemahaman yang sudah dicapai siswa, membantu guru dalam menyusun strategi pembelajaran berikutnya.

f. Mengevaluasi Pengalaman (Evaluate the Experience) Pada akhir pembelajaran, guru dan siswa melakukan refleksi terhadap aktivitas dan hasil proyek yang sudah dijalankan. Proses refleksi dilakukan baik secara individu.

\section{Sistem Penilaian Proyek}

Penilaian proyek merupakan kegiatan penilaian terhadap suatu tugas yang harus diselesaikan dalam periode/waktu tertentu. Tugas tersebut berupa suatu investigasi sejak dari perencanaan, pengumpulan data, pengorganisasian, pengolahan dan penyajian data. Penilaian proyek dapat digunakan untuk mengetahui pemahaman, kemampuan mengaplikasikan, kemampuan penyelidikan dan kemampuan menginformasikan peserta didik pada mata pelajaran tertentu secara jelas (Kemdikbud, 2013). 
7 Li̊TE, Volume 16 Nomor 1, Maret 2020

Pada penilaian proyek terdapat 3 hal yang perlu dipertimbangkan yaitu:

1. Kemampuan pengelolaan,-- Kemampuan peserta didik dalam memilih topik, mencari informasi dan mengelola waktu pengumpulan data serta penulisan laporan.

2. Relevansi,- Kesesuaian dengan mata pelajaran, dengan mempertimbangkan tahap pengetahuan, pemahaman dan keterampilan dalam pembelajaran.

3. Keaslian,- Proyek yang dilakukan peserta didik harus merupakan hasil karyanya, dengan mempertimbangkan kontribusi guru berupa petunjuk dan dukungan terhadap proyek peserta didik (Kemdikbud, 2013).

\section{METODE PENELITIAN}

Metode yang digunakan dalam makalah ini adalah deskriptif kualitatif yaitu menjelaskan data-data dengan menggunakan deskripsi kalimat bukan dengan angka (Ratna, 2009). Data-data yang berhubungan dengan topik dalam makalah ini diperoleh melalui proses dan hasil pembelajaran pada mata kuliah English Drama Appreciation dengan menggunakan metode berbasis projek. Data-data tersebut merupakan komponen utama dalam deskripsi topic utama makalah yang terdiri dari cerita atau naskah, tokoh, pelataran dan atribut pementasan. Adapun yang menjadi pelaku dalam drama wisata sastra tersebut adalah mahasiswa peminatan ilmu sastra pada program studi sastra Inggris semester V.

Persiapan pementasan dalam pembelajaran berbasis projek tersebut dilakukan dengan tahapan-tahapan perencanaan, pe;aksanaan dan penilaian. Langkah-langkah dalam perencanaan disesuaikan dengan teori dalam Project Based Learning yang dikembangkan oleh The George Lucas Educational Foundation (2005) dalam www.eurekapendidikan.com. Langkah-langkah tersebut meliputi penentuan pertanyaan mendasar sebagai acuan dalam perencanaan, Hasil dari penentuan pertanyaan tersebut menjadi dasar acuan dalam desain proyek yang kemudian memunculkan jadwal sebagai acuan monitoring. 
Haryati Sulistyorini, Pembelajaran Berbasis Projek (Project Based Learning) pada Pengajaran English Drama Appreciation, Menggunakan Media Pementasan Drama Berbahasa Inggris 'Sangkuriang'

Pada tahap penentuan pertanyaan dasar dilakukan pemahaman naskah dan cerita kepada mahasiswa. Pada tahap tersebut dilakukan tes kemampuan mahasiswa dalam memahami cerita yang akan dibawakan. Pemahaman akan unsur kepariwisataan juga ditekankan supaya misi dalam memajukan pariwisata lewat cerita legenda tersebut dapat tercapai sesuai dengan yang diinginkan. Selanjutnya tahap desain proyek yang dalam tahap tersebut calon pemain dan divisi artistik harus benarbenar mampu menyelami legenda berikut budayanya, pelataran tempatnya juga kondisi sosial budaya masyarakat Jawa Barat tempat legenda 'Sangkuriang' berasal. Pada tahap tersebut pengajaran dilakukan dengan memberikan gambaran tentang daerah Jawa Barat dan masyarakatnya. Perilaku, kebiasaan dan budaya hidup masyarakat Jawa Barat pada umumnya dan pada masa legenda 'Sangkuriang' dilahirkan juga dipahamkan sebagai bekal wisata sastra. Setelah desain proyek dan pengetahuan dasar tentang cerita dan objek terkait dilakukan, baru kemudian pengajaran masuk pada penentuan jadwal latihan, persiapan dan monitoring.

Metode dalam tahapan-tahapan pengajaran tersebut dipersiapkan selama kurang lebih 6 (enam) bulan atau satu semester dengan mengacu pada hasil akhir yaitu pementasan.

\section{HASIL DAN PEMBAHASAN}

Pertunjukan drama Sangkuriang, The Legend of Tangkuban Parahu adalah sebuah produk lokal yang dipentaskan dengan menggunakan bahasa internasional. Pementasan drama yang merupakan projek mata kuliah English Drama Appreciation tersebut diikuti oleh mahasiswa semester V program studi sastra Inggris Fakultas Ilmu Budaya Unuversitas Dian Nuswantoro dengan alokasi waktu berdurasi selama 60 menit. Tujuan pemilihan topi cerita Sangkuriang adalah dimaksudkan agar mahasiswa sebagai peserta didik dan generasi muda lebih mencintai produk sastra dari negeri sendiri (sastra lokal). Selain itu, tujuan lain dari penentuan topik cerita Sangkuriang tersebut adalah untuk mengenalkan produk lokal Indonesia pada dunia Internasional dikarenakan pementasan drama tersebut dikemas dengan menggunakan bahasa Inggris. Drama Sangkuriang yang mengangakat tema tentang hikayat 
terjadinya gunung Tangkuban Perahu di Jawa Barat tersebut adalah salah satu bentuk apresiasi sastra yang dapat berperan juga dalam pariwisata. Melalui proses pertunjukan drama tersebut, penonton dapat melakukan wisata sastra karena pada dasarnya dengan membaca karya sastra seperti legenda Sangkuriang tersebut kita dapat melakukan wisata sastra yang aktual. 'Wisata Sastra' menurut Robinson dan Andersen dalam Harsono yang disampaikan pada Seminar Nasional tentang Peran Sastra dan Budaya dalam Pengembangan Pariwisata bahwa wisata sastra memiliki aspek-aspek yang berhubungan dengan warisan wisata seperti tradisi, rumah, adat istadat, selain dikatakan bahwa wisata sastra adalah berkenaan dengan perjalanan wisata.

Pertunjukan Drama Sangkuriang, The Legend of Tangkuban Parahu tersebut secara tidak langsung akan membawa kita pada perjalanan wisata Gunung Tangkuban Perahu terletak di Jawa Barat. Perjalanan wisata tersebut bertujuan untuk mengenalkan pada masyarakat luas bahwa terdapat aset wisata yang potensial yang merupakan hikayat terjadinya Gunung Tangkuban Perahu. Melalui pementasan drama Sangkuriang tersebut diharapkan objek wisata yang sebenarnya sudah dikenal oleh masyarakat, wisatawan baik dalam negeri ataupun asing akan lebih dikenal lagi apalagi penyajiannya disajikan dengan balutan bahasa Internasional. Harsono dalam makalah seminar tentang Peran Sastra dan Budaya dalam Pengembangan Pariwisata mengatakan bahwa wisata sastra merupakan produk dialektika antara sastra dan pariwisata. Wisata sastra merupakan penerapan dari sastra dan pariwisata, di sisi lain wisata sastra merupakan penerapan budaya dalam bidang pariwisata. Hal semacam ini menciptakan hubungan dialektika antara sastra dan pariwisata, sehingga membentuk sintesis yang menguatkan antara sastra dan pariwisata ("Harsono Siswo, Wisata Sastra: Peran Sastra dalam Pengembangan Pariwisata, Seminar Nasional Peran Sastra dan Budaya dalam Pengembangan Pariwisata, Fakultas Ilmu Budaya Universitas Diponegoro Semarang, 30 November 2017.pdf," n.d.). 
Haryati Sulistyorini, Pembelajaran Berbasis Projek (Project Based Learning) pada Pengajaran English Drama Appreciation, Menggunakan Media Pementasan Drama Berbahasa Inggris 'Sangkuriang'

\section{Pengajaran Drama Sangkuriang Berbasis Projek}

Mata kuliah English Drama Appreciation merupakan mata kuliah berbasis projek yang ditawarkan setiap setahun sekali pada mahasiswa peminatan sastra Inggris, program studi Sastra Inggris Universitas Dian Nuswantoro Semarang. Pada pengajaran mata kuliah tersebut mahasiswa diharapkan mampu membuat projek pementasan drama baik Internasional maupun Nasional dengan durasi waktu pementasan selam 90 menit (1.5 jam). Proses persiapan dilakukan dengan mengacu pada tahapan dalam metode pengajaran berbasis projek (Project Based Learning) yaitu penentuan pertanyaan mendasar, desain projek dan monitoring. Persiapan dilakukan selama satu semester (6 bulan) baik untuk pemain (aktor) dan artistik. Drama Sangkuriang yang didesain dengan menggunalan media bahasa Internasional, bahasa Inggris diperankan oleh 3 orang tokoh asli dalam legenda tersebut dan tiga orang tokoh tambahan sebagai variasi cerita. Projek drama tersebut disutradarai oleh Muhammad Arief Nurdiansyah, mahasiswa Fakultas Ilmu Budaya, sastra Inggris, diadaptasi oleh Bayu Ade Prabowo, alumni Fakultas Ilmu Budaya, Sastra Inggris dalam bahasa Inggris.

Mengacu pada hikayat cerita Sangkuriang pada Legenda Sangkuriang:Sejarah Gunung Tangkuban Perahu ("Legenda Sangkuriang:Asal Gunung Tangkuban Perahu," n.d.) diceritakan tentang seorang perempuan cantik bernama Dayang Sumbi, bersuamikan si Tumang, manusia yang karena sebuah kutukan maka wujudnya adalah seekor anjing. Dari perkawinan mereka lahirlah seorang anak laki-laki dan diberi nama Sangkuriang. Sangkuriang yang tumbuh menjadi pemuda dewasa dan gagah suatu hari ketika harus mencarikan hati rusa untuk ibunya tercinta, Dayang Sumbi dihadapkan pada dua situasi menjadikan hati si Tumang sebagai hasil buruannya karena dia tidak juga mendapatkan rusa. Situasi tersebut kemudian membawa cerita pada suatu keadaan yang menyebabkan Dayang Sumbi marah karena perbuatan Sangkuriang dan akhirnya mengusir anak satu-satunya tersebut. Setelah berkelana lama, akhirnya Sangkuriang kembali ke desanya dan mendapatkan seorang perempuan cantik yang tidak lain adalah ibunya sendiri, Dayang Sumbi. Perasaan cinta kemudian muncul dari hati Sangkuriang dan membawa cerita tersebut pada 
konflik yang berkepanjangan hingga sampai pada penyelesaian ketika Dayang Sumbi meminta syarat yang akhirnya ditempuh Sangkuriang. Penyelesaian konflik pada cerita tersebut akhirnya berujung pada kemarahan Sangkuriang yang divisualkan dengan menendang sebuah perahu buatannya yang gagal hingga membentuk sebuah gunung berbentuk perahu terbalik yang kemudian lebih dikenal dengan nama Gunung Tangkuban Parahu. Berdasarkan hikayat cerita tersebut legenda Sangkuriang kemudian diadaptasi oleh penulis naskah dalam bahasa Inggris dengan variasi cerita sebagai bentuk pengembangan sastra lisan.

\section{Tahapan-Tahapan dalam Projek Pementasan Drama Sangkuriang}

Tahapan dalam persiapan projek drama Sangkuriang tersebut dilakukan dengan tujuan untuk mempersiapkan sampai dengan pementasan dengan hasil yang diharapkan. Tahapan-tahapan dalam Project Based Learning yang terbagi dalam tiga tahap diurai selama 16 kali tatap muka dengan asumsi 14 kali pertemuan dikelas dan 2 kali untuk evaluasi.

Seluruh kegiatan pembelajaran English Drama Appreciation diatur dalam Rencana Pembelajaran/Course Outline, yang juga digunakan sebagai monitoring selama perencanaan, pelaksanaan dan evaluasi. Berikut adalah Course Outline English Drama Appreciation untuk pementasan drama Sangkuriang, The Legend of Tangkuban Parahu:

\section{CORSE OUTLINE}

ENGLISH DRAMA APPRECIATION-PROJECT PLAY

SANGKURIANG, THE LEGEND OF TANGKUBAN PARAHU

ENGLISH DEPARTMENT FACULTY OF HUMANITIES

DIAN NUSWANTORO UNIVERSITY

Odd Semester - Academic Year 2017-2018

Sumber : Sillabus English Drama Appreciation Sastra Inggris FIB UDINUS.

\begin{tabular}{clc}
\hline WEEK & DESCRIPTION \\
\hline 1 & Casting & \\
& Job Description & \\
& Director & \\
& Actor and Actress & \\
& Creative Team & \\
& Grading System & \\
& Script Mastering \\
\hline
\end{tabular}


Haryati Sulistyorini, Pembelajaran Berbasis Projek (Project Based Learning) pada Pengajaran English Drama Appreciation, Menggunakan Media Pementasan Drama Berbahasa Inggris 'Sangkuriang'

\begin{tabular}{ll}
\hline 2 & $\begin{array}{l}\text { Mini Presentation (actor, director, script writer) } \\
\text { Content : Mastering General Description of Characters, Content of the Story } \\
\text { Mini Presentation (creative team) } \\
\text { Content : Pre Proposal ; Check List ; PIC ; Budget estimation (pre) }\end{array}$ \\
$4-6$ & $\begin{array}{l}\text { Design a plan for the project } \\
\text { Create a schedule (Time Line) }\end{array}$ \\
Character development \\
8
\end{tabular}$\quad \begin{aligned} & \text { Mid Test - the evaluation is based on the result on week 4-7 } \\
& \text { Character Drill for Director Actor and Actress } \\
& \text { Preparation on Final exam ; Evaluation for the tallent } \\
& \text { Final Proposal Presentation } \\
& \text { (Evaluation for the creative team) } \\
& \text { Final Assessment / Performance }\end{aligned}$

Course Outline yang tersebar dalam 16 kali pertemuan dengan asumsi 14 kali tatap muka dan 2 kali evaluasi dibuat dengan asumsi perencanaan tersebut mampu menjadi pengendali mutu bagi mahasiswa dalam mempersiapkan pertnjukkan drama Sangkuriang the Legend of Tangkuban Parahu tersebut.

\section{Penentuan Pertanyaan (Start with Essential Questions)}

Persiapan awal adalah dengan melakukan casting atau pemilihan pemain untuk menentukan aktor utama dan aktor pendukung. Setelah pemilihan pemain dilakukan dan mendapatkan hasil diharapkan, maka tahap persiapan selanjutnya adalah dengan menentukan divisi artistik.

Pada tahap penentuan pertanyaan tersebut, baik aktor maupun tim divisi diwajibkan mengikuti proses pemahaman naskah sebelum mereka memulai persiapan berikutnya. Tahap tersebut adalah sangat diperlukan agar semua unsur yang terlibat dalam pementasan drama Sangkuriang mampu memberikan perfoma yang lebih bernuansa sesuai dengan daerah tempat legenda tersebut berasal. Pada tahap penentuan pertanyaan tersebut para peserta yang terlibat harus mampu menghadirkan nuansa wisata sastra sehingga diharapkan tujuan dari pementasan drama Sangkuriang berhasil memberikan wacana wisata aktual Gunung Tangkuban Perahu dengan nuansa daerah Jawa Barat. Mahasiswa para peserta projek pementasan drama Sangkuriang tersebut harus mampu mengungkap informasi atas pertanyaanpertanyaan yang berhubungan dengan legenda tersebut. 
Apa saja yang dimaksud dalam wisata sastra pada tahapan ini adalah situasi ketika mahasiswa harus benar-benar mampu membawa diri mereka pada situasi yang sebenarnya. Mereka tidak harus berbicara mengenai kondisi asset wisata di Jawa Barat namun lebih pada bagaimana mengenalkan dan lebih mengenalkan objek wisata Gunung Tangkuban Perahu melalui cerita Sangkuriang tersebut. Apabila para calon pemain dan yang lainnya sudah memiliki pemahaman tentang cerita Sangkuriang dari awal sampai akhir cerita, maka diharapkan tujuan pementasan drama dengan konsep wisata sastra akan bisa tercapai karena peran aktual sastra dalam pariwisata berjalan sesuai yang diharapkan dimana Gunung Tangkuban Perahu tidak hanya dikenal keberadaannya sebagai aset wisata namun juga hikayat yang terkandung didalamnya.

Pemahaman naskah pada tahap ini bertujuan juga untuk membantu bidang artistik dalam mempersiapkan aspek-aspek yang mendukung pertunjukan drama tersebut seperti properti kostum tokoh, musik dan suara pengiring pelengkap adegan, pelataran tempat yang digunakan. Semua komponen tersebut harus disusun sedemikian rupa disesuaikan dengan tema cerita sehingga nuansa daerah asli tempat cerita tersebut berasal bisa benar-benar mencerminkan tempat aslinya dan mampu membawa penonton dalam wisata sastra yang aktual meskipun hanya memlalui karya sastra drama.

Berdasarkan Course Outline Engish Drama Appreciation, pada perkuliahan minggu pertama, mahasiswa dijelaskan tentang gambaran pembagian tugas dan tanggung jawab masing-masing bagian dan peran yang diberikan setelah casting/seleksi dilakukan dan memperoleh hasil. Selain itu komponen penilaian juga dijelaskan sehingga diharapkan mahasiswa mampu mengoptimalkan tugas dan tanggung jawab mereka sesuai dengan tiap-tiap peran. Apabila kegiatan-kegiatan tersebut telah selesai dilakukan kemudian naskah/script cerita diberikan dan dilakukan bedah naskah atau pemahaman naskah untuk mendapatkan hasil yang diinginkan. Pertanyaan-pertanyaan yang sekiranya mendukung dalam proses pemahaman materi juga diberikan mengingat pada tahap awal tersebut mengacu pada penentuan pertanyaan atau start with essential questions. Tahap persiapan awal 
Haryati Sulistyorini, Pembelajaran Berbasis Projek (Project Based Learning) pada Pengajaran English Drama Appreciation, Menggunakan Media Pementasan Drama Berbahasa Inggris 'Sangkuriang'

sampai dengan pemahaman naskah bagi tiap pemeran dan divisi yang sudah ditentukan tersebar dalam 2 (dua) pertemuan atau selama 2 minggu. Pada tahap ini penilaian awal juga sudah dilakukan. Apabila tahap persiapan awal tersebut sudah selesai dilakukan maka kegiatan selanjutnya adalah memasuki tahap desain perencanaan projek.

\section{Mendesain Perencanaan Proyek (Design a Plan for the Project) dan Menyusun Jadwal (Create a Schedule)}

Mendesain perencanaan proyek merupakan tahapan untuk bagian artistik karena pada tahap tersebut mulai disusun rencana atau desain projek. Langkah awal dalam penyusunan desain projek adalah dengan menyusun Time Line atau Jadwal kegiatana yang akan dilakukan mulai dari persiapan awal sampai dengan pementasan. Bukan saja hanya divisi artistik saja yang terlibat namun juga pemain. Desain projek yang disusun harus mampu mengakomodir kebutuhan drama Sangkuriang.

Selain menyusun jadwal persiapan, dalam tahap ini juga di buat perencanaan unsur pendukung drama seperti properti, kostum, make up, pencahayaan dan musik. Karena salah satu tujuan drama Sangkuriang, The Legend of Tangkuban Parahu adalah wisata sastra maka penyediaan unsur-unsur yang yang mendukung pemain dalam membawakan cerita harus benar-benar merepresentasikan kondisi asli daerah wisata yang menjadi pelataran utama drama tersebut. Bagaimana nuansa panggung/stage mampu membawa penonton dalam wisata sastra menjadi pertimbangan utama dalam desain projek. Rasa penasaran penonton tentang aktualitas terjadinya gunung yang sangat terkenal di jawa Barat tersebut harus diutamakan dan menjadi tolok ukur keberhasilan wisata sastra melalu pementasan visualisasi drama. Desain projek tersebut dipersiapkan selama 12 kali pertemuan atau 12 minggu. Selain persiapan desain juga dilakukan persiapan kesiapan pemain dalam perkembangan pemahaman tokoh/character development. Keseluruhan dari pengerjaan desain tersebut dikoordinir oleh seorang pengatur panggung/stage manager. Stage Manager bertanggung jawab dalam kelancaran eperform drama Sangkurian tersebut, mulai dari persiapan sampai dengan pementasan akhir. Segala omponen yangdiperlukan demi 
kelancaran projek pementasan drama tersebut menjadi tanggung jawab semua personil yang terlibat di bawah koordinasi Stage Manager.

Seperti dijelaskan sebelumnya bahwa keberhasilan nuansa wisata sastra adalah menjadi tolok ukur utama dalam pertunjukan drama Sangkuriang, The Legend of Tangkuban Parahu tersebut. Mahasiswa harus benar-benar memahami ikon-ikon dan symbol dalam kandungan cerita yang mungkin saja dapat mencerminkan budaya, tradisi dan kehidupan masyarakat Jawa Barat pada umumnya sehingga bagi penonton yang sudah tahu tempat wisata tersebut akab merasa semakin ingin tahu dan bagi penonton yang belum tahu tentang legenda Sangkuriang tersebut akan menjadi semakin ingin mengunjungi tempat wisata yang legendaris tersebut. Keberhasilan pada tahap tersebut menjadi parameter keberhasilan fungsi sastra dalam wisata sastra di mana pembaca, penonton dan penikmat sastra merasakan berwisata sastra melalui fungsi dialektika antara sastra dan pariwisata.

\section{Monitoring Kemajuan Siswa (Monitor the Students and Progress)}

Tahap monitoring kemajuan siswa merupakan tahapan assessment atau evaluasi mulai dilaksanakan. Evaluasi bisa dilakukan sejak awal persiapan sampai dengan pertunjukan. Secara intensitas evaluasi tahap desain menuju pementasan adalah evaluasi yang besar persentasinya. Hasil dari evaluasi tersebut dirangkum dalam portofolio mahasiswa dan dibuat untuk tiap individunya. Berikut adalah beberapa contoh portofolio yang disesuaikan dengan peran dan fungsi tiap-tiap peserta:

FORM PENILAIAN MAHASISWA (ARTISTIK)

ENGLISH DRAMA APPRECIATION

SANGKURIANG, THE LEGEND OF TANGKUBAN PARAHU

\begin{tabular}{|c|c|c|c|c|c|}
\hline Nama Mahasiswa & $:$ & & & & \\
\hline NIM & : & & & & \\
\hline Divisi & : & & & & \\
\hline \multirow[b]{2}{*}{ Komponen Penilaian } & \multicolumn{4}{|c|}{ Kriteria } & \multirow[b]{2}{*}{$\mathrm{N}$} \\
\hline & $\begin{array}{c}85-95 \\
\text { Sangat Bagus }\end{array}$ & $\begin{array}{c}84-70 \\
\text { Bagus }\end{array}$ & $\begin{array}{c}69-55 \\
\text { Cukup }\end{array}$ & $\begin{array}{l}54-45 \\
\text { Kurang }\end{array}$ & \\
\hline
\end{tabular}


Haryati Sulistyorini, Pembelajaran Berbasis Projek (Project Based Learning) pada Pengajaran English Drama Appreciation, Menggunakan Media Pementasan Drama Berbahasa Inggris 'Sangkuriang'

\begin{tabular}{|c|l|l|l|l|l|}
\hline $\begin{array}{c}\text { Pengetahuan Dasar } \\
(30 \%)\end{array}$ & & & & & \\
\hline Perencanaan (50\%) & & & & & \\
\hline Pencapaian (20\%) & & & & & \\
\hline
\end{tabular}

FORM PENILAIAN MAHASISWA (TALLENT)

ENGLISH DRAMA APPRECIATION

SANGKURIANG, THE LEGEND OF TANGKUBAN PARAHU

\begin{tabular}{ll}
\hline Nama Mahasiswa & $:$ \\
\hline NIM & $:$ \\
\hline Peran & $:$ \\
\hline
\end{tabular}

\begin{tabular}{|c|c|c|c|c|c|}
\hline \multirow[b]{2}{*}{ Komponen Penilaian } & \multicolumn{4}{|c|}{ Kriteria dan Nilai } & \multirow[b]{2}{*}{$\mathrm{N}$} \\
\hline & $\begin{array}{c}85-95 \\
\text { Sangat Bagus }\end{array}$ & $\begin{array}{c}84-70 \\
\text { Bagus }\end{array}$ & $\begin{array}{l}69-55 \\
\text { Cukup }\end{array}$ & $\begin{array}{l}54-45 \\
\text { Kurang }\end{array}$ & \\
\hline $\begin{array}{l}\text { Penguasaan peran dan } \\
\text { penjiwaan terhadap } \\
\text { karakter tokoh yang } \\
\text { dibawakan }(50 \%) \\
\end{array}$ & & & & & \\
\hline $\begin{array}{l}\text { Kreatifitas Gerak, } \\
\text { gimik, dan gerak yang } \\
\text { dimunculkan pada saat } \\
\text { neran }(30 \%)\end{array}$ & & & & & \\
\hline $\begin{array}{l}\text { Ekspresi wajah pada } \\
\text { saat membawakan } \\
\text { peran }\end{array}$ & & & & & \\
\hline $\begin{array}{l}\text { Kemampuan dalam } \\
\text { berdialog/membawakan } \\
\text { dialog }\end{array}$ & & & & & \\
\hline $\begin{array}{l}\text { Kemampuan dalam } \\
\text { berbahasa Inggris }\end{array}$ & & & & & \\
\hline
\end{tabular}

Evaluasi penilaian baik untuk pemain (aktor) maupun artistik. Didasarkan atas kriteria: kemampuan pengelolaan, relevansi dan keaslian. Kemampuan Pengelolaan meliputi persiapan, pembuatan perencanaan (desain dan time line), dan perencanaan 
tujuan akhir. Relevansi adalah kesamaan karakter, pelataran dan unsur lain yang menunjang drama disesuaikan dengan keselarasan tema utama dari cerita Sangkuriang. Pembuatan perlengkapan-perlengkapan yang menunjang perfoma harus diutamakan untuk tidak mennggalkan unsur budaya dan tradisi asli dari cerita tersebut. Keaslian atau Originalitas adalah komponen evaluasi yang berfungsi utuk menilai keaslian dari karay yang akan dipentaskan. Meskipun karya tersebut telah mengalami penambahan variasi baik dari tokoh dan tempatnya, namun kreatifitas yang dikembangkan tersebut harus merupakan karya asli mereka. Selain hal tersebut, keaslian utama cerita Sangkuriang mula dari pemunculan awal sampai tujuan akhir cerita juga asli dan standar, tidak boleh mengalami pergeseran terlalu banyak. Hal tersebut dimaksudkan untuk menghindari asumsi dan apresiasi yang salah dari penonton terhadap cerita asli dan cerita yang dikembangkan. Sebisa mungkin hal tersebut dihindari agar wisata sastra pada legenda Sangkuriang tersebut tetap asli dengan bentuk cerita sebenarnya. Tiap komponen penialaian mempunyai persentase yang berbeda. Kemampuan Pengelolaan diberikan dengan prosentase 25\%, Relevansi $30 \%$ dan keaslian $45 \%$. Hasil keseluruhan dari evaluasi tersebut dirangkum dalam form penilaian portofolio.

\section{Wisata Sastra dan Hasil Penerapan dalam Pembelajaran English Drama Appreciation dengan Menggunakan Metode Pementasan Drama "Sangkuriang"}

Seperti dijelaskan sebelumnya bahwa pada prinsipnya wisata sastra adalah segala sesuatu yang berhubungan dengan sastra dan pariwisata. Bagaimana sastra dapat menjadi media dalam perkembangan dunia pariwisata merupakan fungsi dialektika yang sinergi antara sastra dan pariwisata. Wisata sastra dapat diartikan sebagai perjalanan ke tempat wisata dengan membaca karya-karya sastra. Wisata sastra dengan karya sastra biasa didapat dalam karya berjenis legenda atau flokflok/cerita rakyat.Membaca sebuah legenda di suatu daerah tertentu menjadikan kita akan lebih mengenal daerah bersejarah tersebut meskipun hanya memalui pembacaan karya-karya sastra. 
Haryati Sulistyorini, Pembelajaran Berbasis Projek (Project Based Learning) pada Pengajaran English Drama Appreciation, Menggunakan Media Pementasan Drama Berbahasa Inggris 'Sangkuriang'

Wisata sastra dalam projek pementasan drama Sangkuriang, the Legend of Tangkuban Parahu adalah salah satu upaya Program Studi Sastra Inggris Fakultas Ilmu Budaya Universitas Dian Nuswantoro melalui pembelajaran berbasis projek pada mata kuliah English Drama Appreciation untuk lebih mengenalkan daerah wisata di Jawa Barat yang sudah cukup tekenal dan lebih dikenal lagi dengan legenda/hikayatnya tentang saksi percintaan yang terlarang antara para titisan Dewa, Sangkuriang dan Dayang Sumbi. Pementasan sastra lokal yang dibalut dengan menggunakan bahasa Internasional tersebut diharapkan mampu memberikan apresiasi yang lebih baik dari wisatawan asing maupun domestic untuk lebih mengetahui legenda masyarakat Sunda tersebut.

Pementasan pementasan drama Sangkuriang tersebut terbagi dalam 3 babak dengan durasi perfom selama 90 menit. Pemeran Utama dan pemeran pendukung adalah mahasiswa semester V peminatan Sastra Inggris. Sudut pandang penceritaan drama tersebut adalah dengan menggunakan model naratologi yang dibuka dan ditutup oleh seorang story master atau narrator. Tallent/pemain yang terlibat adalah berjumlah 6 orang, terdiri dari Sangkuriang, Dayang Sumbi, Si Tumang, Ki Jaka dan tokoh jahat Demond King. Meskipun cerita tersebut dipertunjukkan dengan menggunakan media bahasa Inggris, namun keseluruhan komponen drama serta unsur-unsurnya murni berlatar belakang kehidupan masyaratakat Jawa Barat dengan segala tadisinya. Musik yang digunakan sebagai pengantar cerita saja yang kemudian sedikit terdapat kolaborasi antara musik daerah Jawa Barat dan musik yang lebih berifat umum.

Berikut beberapa figure/gambar yang menjelaskan hasil pembelajaran English Drama Appreciation dengan menggunakan Project Based Learning/pembelajaran berbasis projek yaitu pementasan drama Sangkuriang. 
Figure 1: Poster Utama Drama Sangkuriang

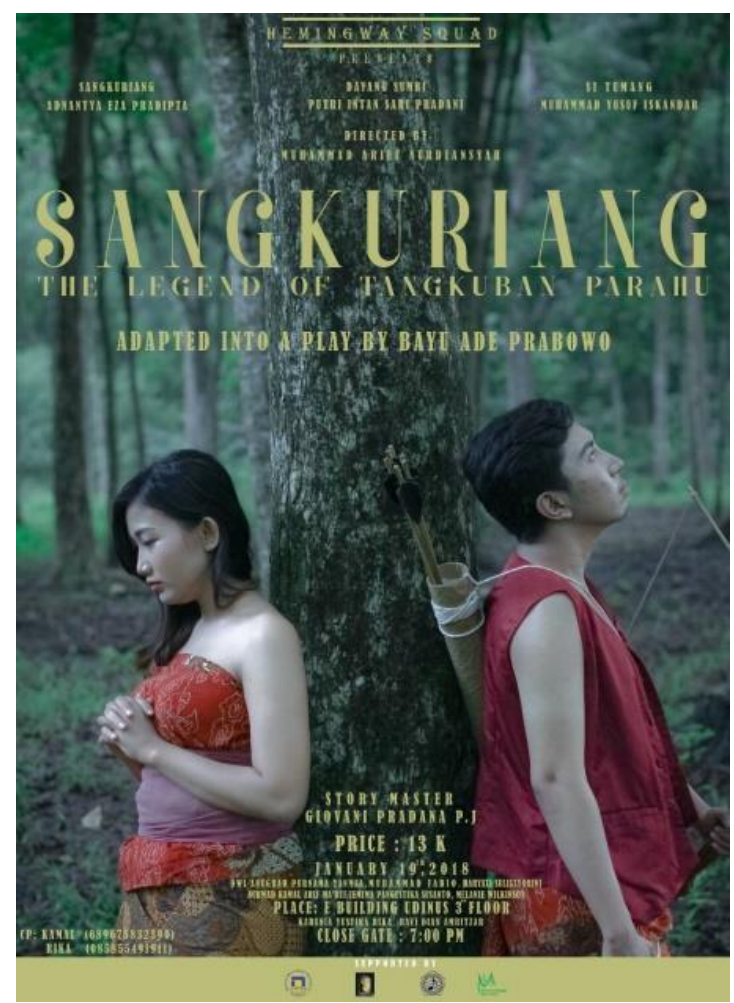

Poster tersebut digunakan sebagai media promosi menjelang pertunjukan drama Samgkuriang. Memuat tokoh utama Sangkuriang dan Dayang Sumbi dengan berlatar belakang hutan sebagai acuan latar tempat saat legenda tersebut terjadi.

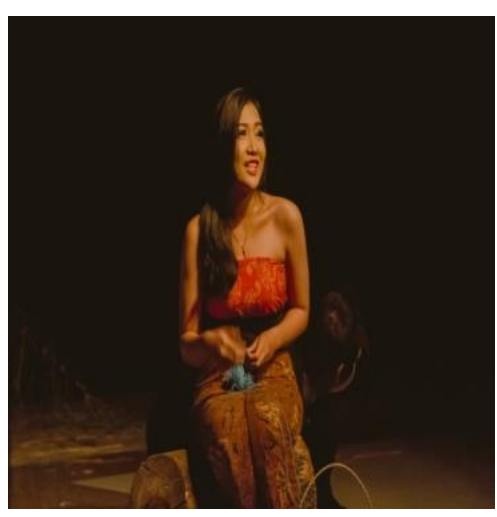

Figure 2. Pemeran utama, Dayang Sumbi pada scene 1

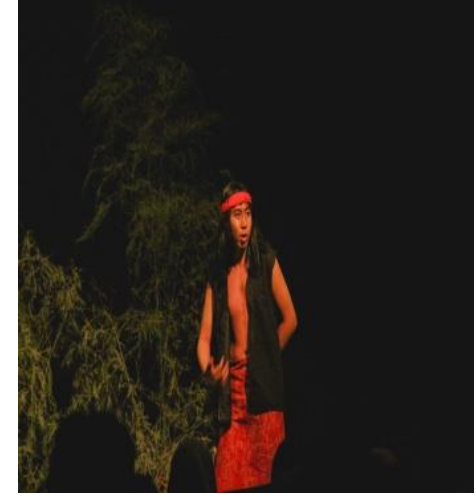

Figure 3. Pemeran Sangkuriang pada scene 3 setelah berkelana kemudian bertemu Dayang Sumbi 
Haryati Sulistyorini, Pembelajaran Berbasis Projek (Project Based Learning) pada Pengajaran English Drama Appreciation, Menggunakan Media Pementasan Drama Berbahasa Inggris 'Sangkuriang'

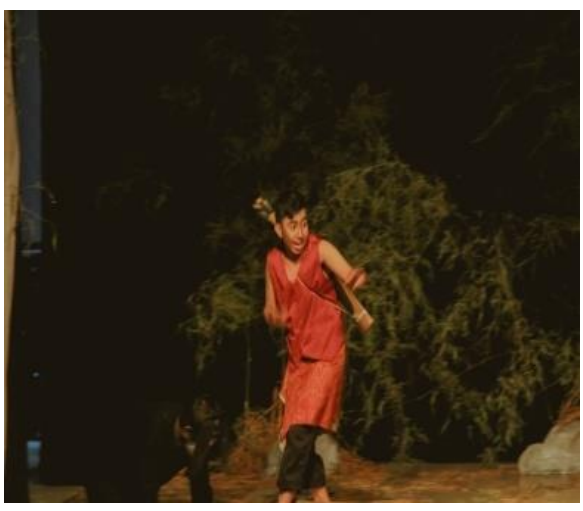

Figure 4. Tokoh Sangkuriang ketika berburu pada scene 1

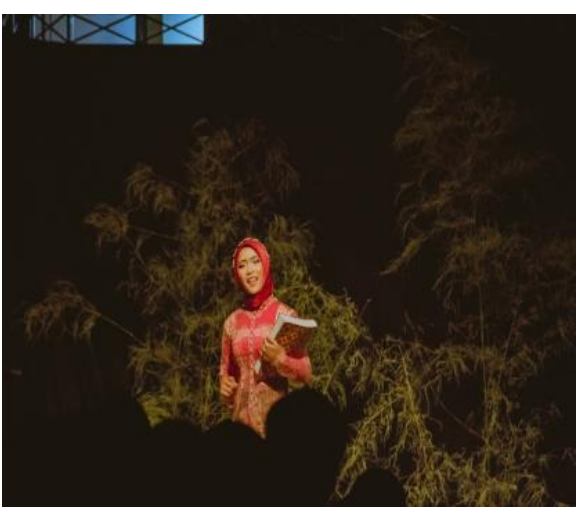

Figure 5. Story Master/Pembawa cerita

\section{SIMPULAN}

Tujuan utama dari pembelajaran mata kuliah berbasis projek tersebut yaitu mengenalkan objek wisata Gunung Tangkuban Perahu yang berlokasi di daerah Jawa Barat. Meskipun drama Sangkuriang dipentaskan dengan menggunakan media bahasa Inggris, namun semua unsur pendukung yang lebih menguatkan situasi dan budaya masyarakat Jawa Barat tetap diutamakan sebagai ikon utama pada drama tersebut.

Berdasarkan hasil diskusi maka dapat disimpulkan pula bahwa pembelajaran mata kuliah English Drama Appreciation dengan dengan mengangkat cerita rakyat 'Sangkuriang' pada pementasan drama berbahasa Inggris merupakan salah satu upaya imu sastra untuk mengenalkan sejarah atau legenda Gunung Tangkuban Perahu yang berlokasi di Propinsi Jawa Barat.

Wisata sastra dalam pembelajaran mata kuliah English Drama Appreciation dengan menggunakan pementasan drama Sangkuriang adalah salah satu upaya dari ilmu sastra dalam memajukan pariwisata. Melalui model pengajaran dan pembelajaran berbasis projek tersebut, diharapkan sastra melalui cerita rakyat Sangkuriang mampu menyumbangkan fungsinya dalam memajukkan dunia 
pariwisata. Projek yang dikerjakan oleh mahasiswa semester V peminatan sastra program studi sastra Inggris tersebut dirancang selama satu semester melalui beberapa tahap yaitu tahap persiapan, perencanaan, dan evaluasi.

\section{REFERENSI}

Christopher Rusell Reaske. (1966). How to Analyze Drama. New York: Monarch Press. Retrieved from https://www.google.co.id/?gws_rd=ssl

Harsono Siswo, Wisata Sastra:Peran Sastra dalam Pengembangan Pariwisata, Seminar Nasional Peran Sastra dan Budaya dalam Pengembangan Pariwisata, Fakultas Ilmu Budaya Universitas Diponegoro Semarang, 30 November 2017.pdf. (n.d.).

Klarer, M. (2004). an Introduction To Literary Studies. https://doi.org/10.4324/9780203414040

Legenda Sangkuriang:Asal Gunung Tangkuban Perahu. (n.d.). Retrieved from https://ppid.bandung.go.id/knowledgebase/legenda-sangkuriang-asal-gunungtangkuban-perahu/

Ratna, I. N. K. (2009). Teori, Metode, dan Teknik Penelitian Sastra dari Strukturalisme hingga Postrukturalisme: Perspektif Wacana Naratif.

Christopher Rusell Reaske. (1966). How to Analyze Drama. New York: Monarch Press. Retrieved from https://www.google.co.id/?gws_rd=ssl

Harsono Siswo, Wisata Sastra:Peran Sastra dalam Pengembangan Pariwisata, Seminar Nasional Peran Sastra dan Budaya dalam Pengembangan Pariwisata, Fakultas Ilmu Budaya Universitas Diponegoro Semarang, 30 November 2017.pdf. (n.d.).

Klarer, M. (2004). an Introduction To Literary Studies. https://doi.org/10.4324/9780203414040

Legenda Sangkuriang:Asal Gunung Tangkuban Perahu. (n.d.). Retrieved from https://ppid.bandung.go.id/knowledgebase/legenda-sangkuriang-asal-gunungtangkuban-perahu/

Ratna, I. N. K. (2009). Teori, Metode, dan Teknik Penelitian Sastra dari Strukturalisme hingga Postrukturalisme: Perspektif Wacana Naratif. 